\title{
An Outbreak of Serratia marcescens in a Moroccan Neonatal Intensive Care Unit
}

\author{
Abdellatif Daoudi (D), ${ }^{1,2}$ Fatiha Benaoui $\mathbb{D}^{1,2}$ Nadia El Idrissi Slitine, ${ }^{1,2}$ Nabila Soraa, ${ }^{3}$ \\ and Fadl Mrabih Rabou Maoulainine ${ }^{1,2}$ \\ ${ }^{1}$ Neonatal Intensive Care Unit, Mother-Child Center, Mohammed VI University Medical Hospital of Marrakesh, Morocco \\ ${ }^{2}$ Research Team Childhood, Health and Development, Faculty of Medicine and Pharmacy Cadi Ayyad University, Morocco \\ ${ }^{3}$ Biology Laboratory, Mother-Child Unit, Mohammed VI University Medical Hospital of Marrakesh, Morocco
}

Correspondence should be addressed to Abdellatif Daoudi; abdellatif.daoudi90@gmail.com

Received 25 March 2018; Revised 30 July 2018; Accepted 13 September 2018; Published 1 November 2018

Academic Editor: Gabriel Dimitriou

Copyright (c) 2018 Abdellatif Daoudi et al. This is an open access article distributed under the Creative Commons Attribution License, which permits unrestricted use, distribution, and reproduction in any medium, provided the original work is properly cited.

\begin{abstract}
Serratia marcescens (S. marcescens) is an Enterobacteriaceae microorganism that is widespread in the environment, which may be the source of nosocomial infections, rare in the newborn but severe, and often in the form of outbreaks. The aim of our study is to report our experience, during an outbreak of $S$. marcescens, to show the severity of this germ, with review of the literature. Our study was retrospective, including 8 newborns with $S$. marcescens nosocomial infection, collected in the neonatal intensive care unit of Mohammed VI University Medical Hospital, during the epidemic period, over a period of 2 months (July and August 2016). The mean gestational age of the cases was 36 weeks of amenorrhea. Boys accounted for $75 \%$ of the cases. The average weight was 1853 grams. All the patients were initially placed under empiric antibiotic therapy based on ceftriaxone and gentamicin. The mean duration of nosocomial infection, diagnosed in all cases by blood cultures, was 7 days. The strains of $S$. marcescens were in $75 \%$ of the cases sensitive to the cephalosporins, intermediate sensitivity in $12.5 \%$ of cases and resistant in $12.5 \%$ of cases. The outcome was fatal in $62.5 \%$ of cases. S. marcescens nosocomial infections are often reported on epidemic series, and their eradication is not always easy.
\end{abstract}

\section{Introduction}

Nosocomial infections in neonatal intensive care unit still represent a public health problem by the morbidity and mortality that they engender. The most incriminated pathogens are Enterobacteriaceae that belong to the Gramnegative bacillus (GNB) family, especially in developing countries, and they can represent $51.5 \%$ of the cases [1]. Among the GNB, Serratia marcescens (S. marcescens) is a ubiquitous opportunistic pathogen, whose eradication of the environment is very difficult [2]. Nosocomial infections with $S$. marcescens are rare in newborns and often described as outbreaks $[2,3]$. Infection can occur in the newborn as pneumonia, bacteremia, conjunctivitis, urinary tract infections, and even gastroenteritis. The outcome of these infections is often serious, with a heavy morbidity and mortality; whence, the importance of initiating, as soon as the diagnosis of this germ is made, controls measures before the propagation which can be spectacular.

The aim of this study is to share our experience of nosocomial infections due to this germ, to show the gravity of this germ, with a review of the literature.

\section{Patients and Methods}

This is a descriptive retrospective study, performed in the neonatal intensive care unit (NICU) of Mohammed VI University Medical Hospital, Marrakesh, Morocco. During the epidemic period of this germ, July and August 2016, the population in our study included neonates hospitalized in the NICU, whose postnatal age ranged from 0 to 28 days with the diagnosis of nosocomial 
infection of S. marcescens, which was made by the positivity of bacteriological samples at least 48 hours after admission to our NICU. Data collection was done using an individual record.

The literature review was done on PubMed including writings describing Serratia marcescens outbreaks in neonates in the NICU.

\section{Results}

We collected eight cases, which were included during the study period, July and August 2016, which corresponded to the epidemic period of $S$. marcescens bacteremia.

The epidemic began in early July 2016 in a premature 33.9 GA admitted for hyaline membrane disease, which showed after 3 days of his hospitalization signs of sepsis with isolation of Serratia marcescens in the blood culture, and other cases were diagnosed throughout the July period.

The mean gestational age of our patients was 36 weeks (wk), with extremes ranging from 33.2 to $40.8 \mathrm{wk}$. Newborns were premature in $75 \%$ of cases. The sex ratio (boy/girl) was 3. The weight ranged from 1130 grams to 3600 grams with an average weight of 1853 grams. Hyaline membrane disease was the most diagnosis of hospitalization in $62.5 \%$ of cases and neonatal pulmonary infection in $37.5 \%$ of cases (Table 1).

On admission, all patients were treated with ceftriaxone and gentamicin antibiotics, and $87.5 \%$ of cases were artificially ventilated. The diagnosis of nosocomial infection was made over an average of 7 days of hospitalization, with extremes ranging from 3 days to 12 days. The diagnosis was made in the presence of clinical signs and/or biological abnormalities on the hemogram or ascension C-reactive protein with $S$. marcescens-positive blood cultures. Isolated S. marcescens strains were susceptible in $75 \%$ of cases to $3 \mathrm{rd}$ generation cephalosporins and all susceptible to imipenem, to ciprofloxacin, and to aminoglycosides (amikacin and gentamicin), but all were resistant to colistin (Table 2). After diagnosis of nosocomial $S$. marcescens infection, all patients were treated with imipenem and amikacin. The outcome was favorable in $37.8 \%$ of the cases, and the death was reported in $62.5 \%$. The average hospital stay was 22.75 days, with extremes ranging from 12 days to 34 days.

\section{Discussion}

Nosocomial infections in neonatal intensive care units are a public health problem because of their heavy consequences on morbidity and mortality and the important cost they generate [1]. S. marcescens has emerged as a currently recognized pathogen for nosocomial infection in neonates, especially in epidemic form [4], which has also been reported in our experience. We collected 8 cases of $S$. marcescens bacteremia for 2 months. A similar report was published in 2010 by Gulcin Bayramoglu et al., comprising 9 cases, in neonatal intensive care unit over a period of 36 days [5].

Bacteriologically, Serratia is a Gram-negative bacillus belonging to the Enterobacteriaceae family, saprophytic genus, and widely found in the environment.
In S. marcescens outbreaks, sources of contamination reported in the literature were different: catheters, heparin solution, dialysis machine, propofol, liquid soap [6-11], and of course the manual transmission due to lack hospital hygiene.

The statistically significant risk factors of infection nosocomial to Serratia according to Al Jarousha and coworkers were low birth weight less than $1500 \mathrm{~g}$, gestational age greater than 37 weeks, and mechanical ventilation [4]. Other risk factors that are common to all nosocomial infections are long hospital stay, antibiotic prescription, and the use of invasive methods: umbilical catheter, intubation, bladder catheterization, and parenteral nutrition [12]. However, our population was $75 \%$ premature and $87.5 \%$ artificially ventilated, the average weight recovered was $1850 \mathrm{~g}$, and only one newborn had an umbilical vein catheter.

In our study, we isolated Serratia in blood cultures. This germ could be responsible for septicemia, pneumonia, conjunctivitis, urinary tract infections, and even gastroenteritis in newborns. In a study by Morillo et al., the clinical manifestations found in the ascending order were pneumonia, conjunctivitis, septicemia, and finally urinary tract infection [13]. Cerebromeningeal complications have recently been reported to be more frequent with Serratia marcescens, namely, meningitis, brain abscess, and empyema, and it is recommended to perform systematically brain imaging and more particularly transfontanellar ultrasound even in the absence of neurological signs [14].

With regard to the resistance of $S$. marcescens to antibiotics, high resistance to cephalosporins is often reported which can reach up to $100 \%[13,15]$. In our study, the cephalosporin resistance rate was lower and all strains were sensitive to imipenem and ciprofloxacin, which is consistent with the results reported by $\mathrm{Al}$ Jarousha who reported a sensitivity of $90 \%$ to imipenem and $76 \%$ to ciprofloxacin [4]. As for colistin, all our isolated strains were resistant concordant with the results of Buffet-Battailon et al. [16] and those of Adjidé et al. [15]. In addition to the resistance of Serratia to antibiotics, its severity is clear in light of the high mortality rates reported, which varies from $14.3 \%$ to $62.5 \%$ of cases $[4,5,14,15,17-20]$ but in our study, we have a higher rate which was $62.5 \%$ (Table 3 ).

To cope with these epidemics, a number of measures were taken as soon as the first case is diagnosed, mainly the education of medical and paramedical staff on the importance of hand hygiene, the use of double protection by gloves, the technical and geographical isolation of the infected patients, and the disinfection of any surface or equipment likely to be contaminated. We achieved all these measures, which allowed a control of the epidemic at the end of August 2016.

\section{Conclusion}

Nosocomial infections with Serratia marcescens are beginning to take a large scale in neonatal intensive care unit, often in epidemic form. They are responsible for significant morbidity and mortality and pose the problem of acquiring 
Table 1: Patients' demographic data.

\begin{tabular}{|c|c|c|c|c|c|c|c|c|c|}
\hline $\begin{array}{l}\text { Patient } \\
\text { no. }\end{array}$ & Diagnosis & $\begin{array}{l}\text { Gestational } \\
\text { age (weeks) }\end{array}$ & $\begin{array}{l}\text { Weight } \\
\text { (grams) }\end{array}$ & $\begin{array}{l}\text { Method } \\
\text { of } \\
\text { delivery }\end{array}$ & $\begin{array}{l}\text { Antibiotic } \\
\text { prescription }\end{array}$ & $\begin{array}{l}\text { Mechanical } \\
\text { ventilation }\end{array}$ & $\begin{array}{c}\text { Umbilical } \\
\text { catheterization }\end{array}$ & $\begin{array}{c}\text { Day of infection } \\
\text { with Serratia } \\
\text { marcescens }\end{array}$ & Outcome \\
\hline 1 & $\begin{array}{l}\text { Neonatal } \\
\text { pulmonary } \\
\text { infection }\end{array}$ & 40.8 & 3600 & Caesarean & Yes & Yes & None & 12 & Favorable \\
\hline 2 & $\begin{array}{l}\text { Hyaline } \\
\text { membrane } \\
\text { disease }\end{array}$ & 33.2 & 1130 & $\begin{array}{l}\text { Vaginal } \\
\text { delivery }\end{array}$ & Yes & Yes & None & 7 & Favorable \\
\hline 3 & $\begin{array}{l}\text { Hyaline } \\
\text { membrane } \\
\text { disease }\end{array}$ & 33.9 & 1300 & $\begin{array}{l}\text { Vaginal } \\
\text { delivery }\end{array}$ & Yes & Yes & None & 3 & Death \\
\hline 4 & $\begin{array}{l}\text { Neonatal } \\
\text { pulmonary } \\
\text { infection }\end{array}$ & 34.6 & 1800 & $\begin{array}{l}\text { Vaginal } \\
\text { delivery }\end{array}$ & Yes & Yes & None & 6 & Favorable \\
\hline 5 & $\begin{array}{l}\text { Hyaline } \\
\text { membrane } \\
\text { disease }\end{array}$ & 35,3 & 1600 & $\begin{array}{l}\text { Vaginal } \\
\text { delivery }\end{array}$ & Yes & Yes & None & 5 & Death \\
\hline 6 & Prematurity & 34.6 & 1400 & $\begin{array}{l}\text { Vaginal } \\
\text { delivery }\end{array}$ & Yes & Yes & None & 8 & Death \\
\hline 7 & Prematurity & 35.9 & 1800 & $\begin{array}{l}\text { Vaginal } \\
\text { delivery }\end{array}$ & Yes & None & None & 5 & Death \\
\hline 8 & $\begin{array}{l}\text { Neonatal } \\
\text { pulmonary } \\
\text { infection }\end{array}$ & 40 & 2200 & $\begin{array}{l}\text { Vaginal } \\
\text { delivery }\end{array}$ & Yes & Yes & None & 11 & Death \\
\hline
\end{tabular}

TABle 2: Susceptibility to antibiotics of Serratia marcescens.

\begin{tabular}{lccc}
\hline Antibiotic & & Sensitivity of S. marcescens \\
Intermediary & Resistance \\
\hline Amoxicillin & Sensitivity & None & $100 \%$ \\
Piperacillin & None & None & $25 \%$ \\
Cefotaxime & $75 \%$ & $12.5 \%$ & None \\
Ceftazidime & $87.5 \%$ & $12.5 \%$ & None \\
Imipenem & $87.5 \%$ & None & None \\
Ciprofloxacin & $100 \%$ & None & None \\
Gentamicin & $100 \%$ & None & None \\
Amikacin & $100 \%$ & None & $100 \%$ \\
Colistin & $100 \%$ & None & \\
\hline
\end{tabular}

TABLE 3: Summary of outbreaks caused by S. marcescens reported in the literature in comparison with our experience.

\begin{tabular}{|c|c|c|c|c|}
\hline Series & Country/city & Year & Number of cases & Outcome \\
\hline Al Jarousha et al. [4] & Palestine/Gaza & 2008 & 159 & 70 died \\
\hline Chemsi et al. [18] & Morocco/Casablanca & 2013 & 9 & 5 died \\
\hline Madide and Smith [14] & South Africa/Cape Town & 2015 & 5 & 3 died \\
\hline Polilli et al. [19] & Italy/Pescara & 2011 & 6 & 2 died \\
\hline Gulcin Bayramoglu et al. [5] & Turkey/Trabzon & 2006 & 9 & 3 \\
\hline Walter Zingg et al. [20] & Switzerland/Geneva & 2013 & 20 & None died \\
\hline Our cases & Morocco/Marrakesh & 2016 & 8 & 5 died \\
\hline
\end{tabular}

antibiotic resistance. For this reason, prevention is the best method to fight them.

\section{Data Availability}

The data used to support the findings of this study are available from the corresponding author upon request.

\section{Conflicts of Interest}

The authors declare that they have no conflicts of interest.

\section{References}

[1] M. Chemsi, K. Zerouali, I. Chahid et al., "Incidence des infections bactériennes nosocomiales, Hôpital d'enfants 
Abderrahim Harouchi, CHU Ibn Rochd, Casablanca, Maroc," Journal de Pédiatrie et de Puériculture, vol. 26, no. 1, pp. 11-18, 2013.

[2] C. Montagnani, P. Cocchi, L. Lega et al., "Serratia marcescens outbreak in a neonatal intensive care unit: crucial role of implementing hand hygiene among external consultants," BMC Infectious Diseases, vol. 15, no. 1, p. 11, 2015.

[3] S. Ktari, F. Mahjoubi, B. Mnif, H. Kallel, M. Bouaziz, and A. Hammami, "Investigation de trois épidémies d'infections nosocomiales à Serratia marcescens survenues dans le service de réanimation-CHU de Sfax Tunisie," La Tunisie Médicale, vol. 88, no. 7, pp. 501-506, 2010.

[4] A. M. Kh. Al Jarousha, I. A. El Qouqa, A. H. N. El Jadba, and A. S. Al Afif, "An outbreak of Serratia marcescens septicaemia in neonatal intensive care unit in Gaza City, Palestine," Journal of Hospital Infection, vol. 70, no. 2, pp. 119-126, 2008.

[5] G. Bayramoglu, K. Buru, U. Dinc, M. Mutlu, G. Yilmaz, and Y. Aslan, "Investigation of an outbreak of Serratia marcescens in a neonatal intensive care unit," Journal of Microbiology, Immunology and Infection, vol. 44, no. 2, pp. 111-115, 2011.

[6] E. R. Van der Vorm and C. Woldring-Zwaan, "Source, carriers, and management of a Serratia marcescens outbreak on a pulmonary unit," Journal of Hospital Infection, vol. 52, no. 4, pp. 263-267, 2002.

[7] G. Perotti, M. E. Bernardo, M. Spalla, C. Matti, M. Stronati, and L. Pagani, "Rapid control of two outbreaks of Serratia marcescens in a Northern Italian neonatal intensive care unit," Journal of Chemotherapy, vol. 2, pp. 56-60, 2007.

[8] C. Sartor, V. Jacomo, C. Duvivier, H. Tissot-Dupont, R. Sambuc, and M. Drancourt, "Nosocomial Serratia marcescens infections associated with extrinsic contamination of a liquid nononmedical soap," Infection Control and Hospital Epidemiology, vol. 21, no. 3, pp. 196-199, 2000.

[9] M. L. Manning, L. K. Archibald, L. M. Bell, S. N. Banerjee, and W. R. Jarvis, "Serratia marcescens transmission in a pediatric intensive care unit: a multifactorial occurrence," American Journal of Infection Control, vol. 29, no. 2, pp. 115-119, 2001.

[10] B. Henry, C. Plante-Jenkins, and K. Ostrowska, "An outbreak of Serratia marcescens associated with the anesthetic agent propofol," American Journal of Infection Control, vol. 29, no. 5, pp. 312-315, 2001.

[11] T. Tanaka, H. Takahashi, J. M. Kobayashi, T. Ohyama, and N. Okabe, "A nosocomial outbreak of febrile bloodstream infection caused by heparinized-saline contaminated with Serratia marcescens, Tokyo, 2002," Japanese Journal of Infectious Diseases, vol. 57, no. 5, pp. 189-192, 2004.

[12] M. Doaa and S. Omnia, "Bacterial nosocomial infections in neonatal intensive care unit, Zagazig University Hospital, Egypt," Egyptian Pediatric Association Gazette, vol. 62, no. 34, pp. 72-79, 2014.

[13] Á. Morillo, V. González, J. Aguayo et al., "A six-month Serratia marcescens outbreak in a neonatal intensive care unit," Enfermedades Infecciosas y Microbiología Clínica, vol. 34, no. 10, pp. 645-651, 2016.

[14] A. Madide and J. Smith, "Intracranial complications of Serratia marcescens infection in neonates," South African Medical Journal, vol. 106, no. 4, 2016.

[15] C. C. Adjidé, V. Li-Thiao-Te, M. Biendo, B. Weibel, G. Laurans, and G. Krim, "Étude cas-témoins d'une épidémie à Serratia marcescens dans un service de réanimation pédiatrique," Pathologie Biologie, vol. 52, no. 8, pp. 423-424, 2004.

[16] S. Buffet-Bataillon, V. Rabier, P. Bétrémieux et al., "Outbreak of Serratia marcescens in a neonatal intensive care unit: contaminated unmedicated liquid soap and risk factors," Journal of Hospital Infection, vol. 72, no. 1, pp. 17-22, 2009.

[17] U. Arslan, I. Erayman, S. Kirdar et al., "Serratia marcescens sepsis outbreak in a neonatal intensive care unit," Pediatrics International, vol. 52, no. 2, pp. 208-212, 2010.

[18] M. Chemsi, H. Hamid, and S. Houari, "An outbreak of Serratia marcescens on the neonatal unit: description and investigations," Journal of Infectious Diseases and Therapy, vol. 4, no. 6, 2016

[19] E. Polilli, G. Parruti, P. Fazii et al., "Rapidly controlled outbreak of Serratia marcescens infection/colonisations in a neonatal intensive care unit, Pescara General Hospital, Pescara, Italy, April 2011," Eurosurveillance, vol. 16, no. 24, 2011.

[20] Z. Walter, I. Soulake, D. Baud et al., "Management and investigation of a Serratia marcescens outbreak in a neonatal unit in Switzerland-the role of hand hygiene and whole genome sequencing-R1, ARIC-D-17-00143," Antimicrobial Resistance and Infection Control, vol. 6, no. 1, p. 125, 2017. 


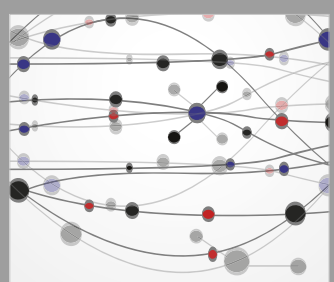

The Scientific World Journal
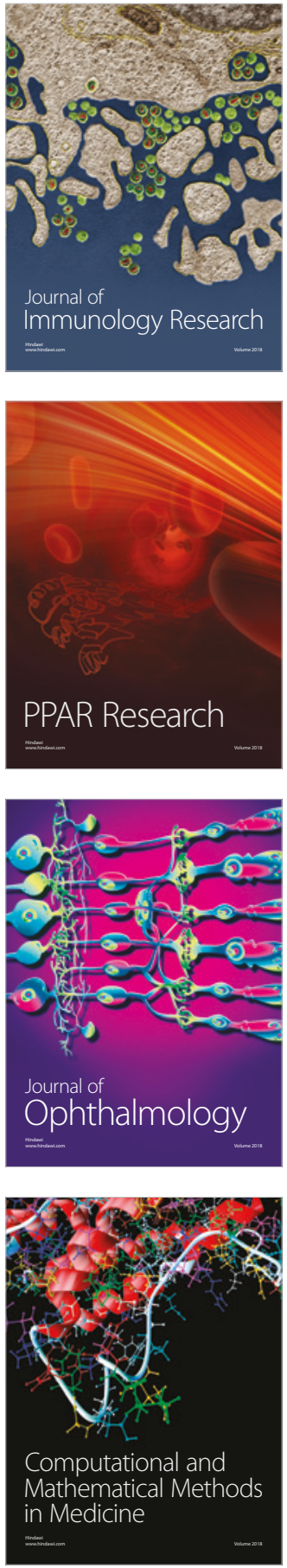

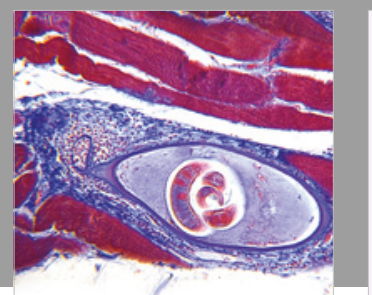

Gastroenterology Research and Practice

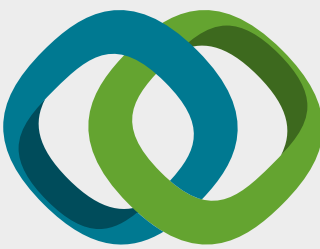

\section{Hindawi}

Submit your manuscripts at

www.hindawi.com
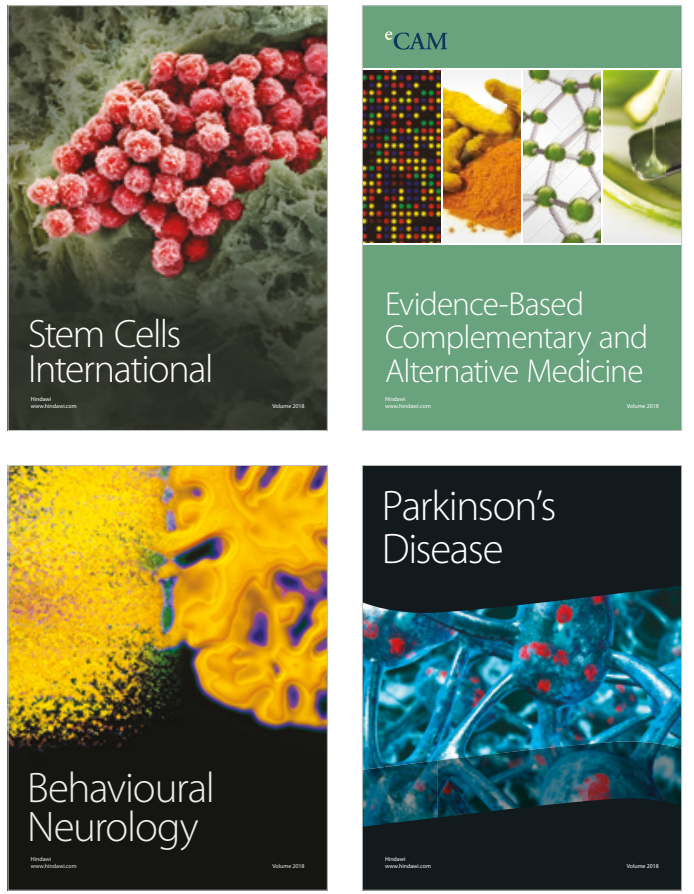

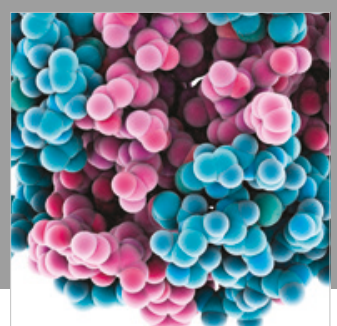

ournal of

Diabetes Research

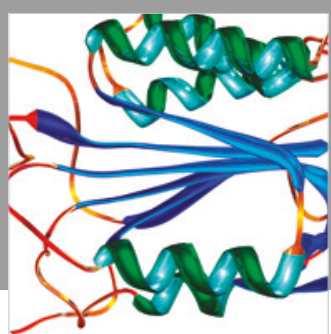

Disease Markers
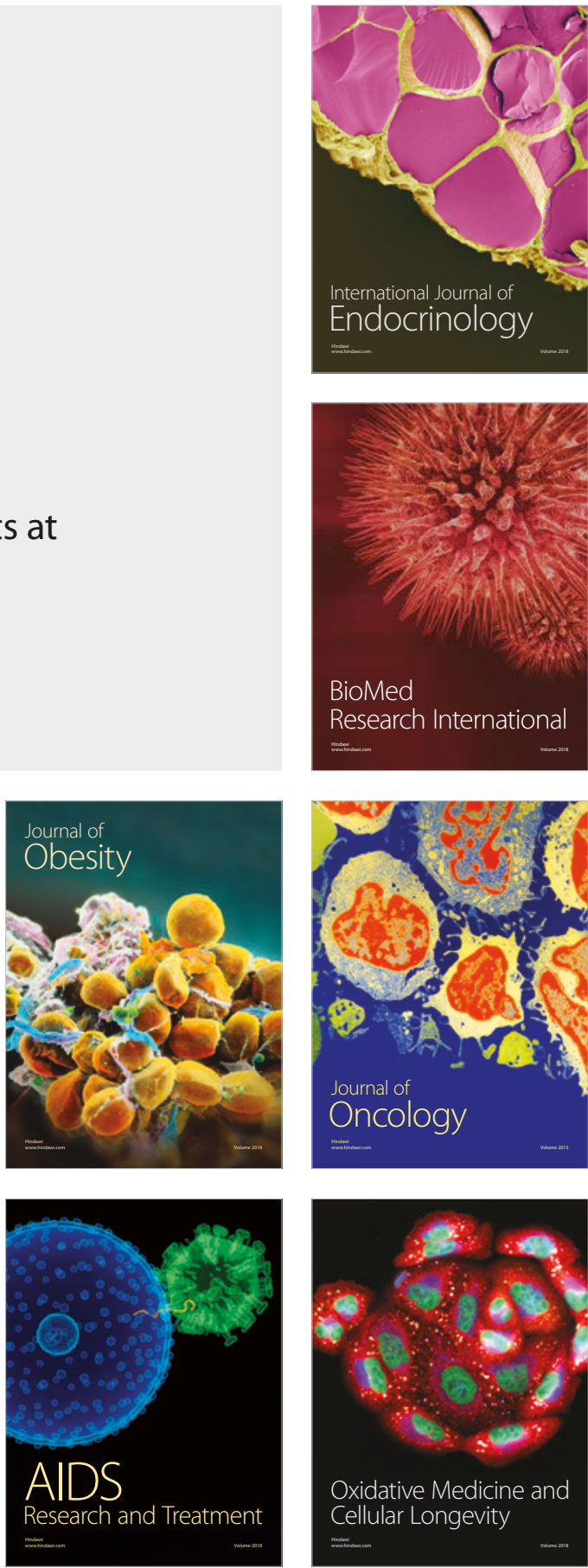